\title{
Evaluasi Kinerja Efisiensi Energi Mesin Bubut Melalui Penilaian Indikasi Specific Energy Consumption
}

\author{
HERMAN BUDI HARJA, MOHAMMAD FAUZI, ASEP FATHAN
}

Jurusan Teknik Manufaktur, Politeknik Manufaktur Bandung, Indonesia

Email: herman@polman-bandung.ac.id

Received 15 September 2020 | Revised 30 Desember 201x| Accepted 29 Desember 2020

\begin{abstract}
ABSTRAK
Kondisi ketidakselarasan sistem transmisi pulley-belt pada mesin bubut berpengaruh terhadap nilai inefisiensi konsumsi energi mesin perkakas. Penelitian ini bertujuan untuk melakukan kajian evaluasi kinerja efisiensi energi mesin bubut pada kondisi sistem transmisi pulley-belt mesin yang selaras dan tidak selaras. Kajian ini menggunakan metoda penilaian indikasi specific energy consumption (SEC) dari proses pemesinan bubut. Nilai total konsumsi energi saat proses pemotongan diukur menggunakan power analyzer, dan diolah menjadi nilai data SEC, kemudian dianalisis menggunakan Data Envelopment Analysis untuk mendapatkan harga referensi. Penilaian skor penurunan energi setiap mesin diperoleh dengan membandingkan jarak nilai SEC setiap mesin terhadap nilai referensi. Obyek penelitian menggunakan lima buah mesin bubut uji berkapasitas daya medium. Hasil kajian menunjukkan bahwa pada kondisi ketidakselarasan sistem transmisi pulley-belt menyebabkan terjadinya inefisiensi energi mesin bubut sebesar 5\%.
\end{abstract}

Kata kunci: Data Envelopment Analysis ,efisiensi energi, ketidakselarasan, SEC

\begin{abstract}
The pulley belt transmission system's misalignment condition on turning machine affects the low-efficiency value of machine tool energy consumption. This study aims to evaluate the energy efficiency of a lathe in the alignment and misalignment of the pulley-belt transmission system. This study used a method of assessing the specific energy consumption (SEC) of the lathe machining process. During the cutting process, the total energy consumption value is measured using a power analyzer and processed into SEC data values, then analyzed using Data Envelopment Analysis to obtain a reference value. The assessment is obtained by comparing the distance between each machine's SEC value and the reference value. The case study's object was conducted on five test lathes with medium power capacity. The study results show that the pulleybelt transmission system's misalignment causes the lathe's energy inefficiency of more than $5 \%$.
\end{abstract}

Keywords: Data Envelopment Analysis, efficiency energy, misalignment, SEC 
Harja $d k k$.

\section{PENDAHULUAN}

Pada proses manufaktur dibutuhkan satu atau lebih mekanisme fisika untuk mengubah material menjadi produk tertentu. Energi merupakan bagian dari input proses yang sebagian besar digunakan untuk menghasilkan suatu kerja operasi pemberian nilai tambah pada produk. Pada Gambar 1 ditampilkan aliran input dan output serta energi pada proses manufaktur. Kajian Apostolos menyatakan bahwa pada kenyataannya proses manufaktur hanya menggunakan sebagian energi yang dikonsumsi untuk proses pemberian nilai tambah, sedangkan sebagian energi lainnya digunakan untuk menjadikan kondisi proses stabil dan untuk menjalankan fungsi peralatan (Apostolos, dkk, 2013).

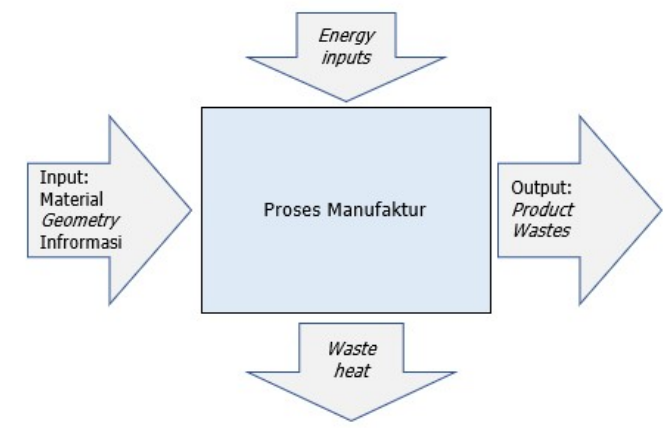

Gambar 1. Aliran Input dan Output serta Energi pada Proses Manufaktur (Apostolos, dkk, 2013)

Kajian assessment proses manufaktur pada umumnya sering diukur menggunakan parameter efisiensi energi dan specific energy consumption. Efisiensi energi merupakan rasio keluaran dan masukan energi, sedangkan specific energy consumption ialah indikator yang dihitung dengan membagi konsumsi energi total dengan indikator fisik tertentu berupa massa ataupun volume.

Beberapa penelitian mengenai evaluasi atau assessment terhadap efisiensi energi proses manufaktur telah banyak dilakukan, baik pada level tertinggi di level factory, level line produksi, level mesin perkakas hingga level proses yang terjadi di mesin perkakas. Kajian efisiensi dapat dimulai dari level terendah yaitu proses pemesinannya, baik pada pemesinan konvensional maupun non konvensional. Kemudian selanjutnya dapat diketahui efisiensi konsumsi energi mesin perkakasnya. Apostolos telah melakukan analisa kualitatif efisiensi energi pada proses laser fitur lubang dan fitur grooving dengan mencermati frekuensi pulsa dan daya laser, termasuk pengaruh yang tidak langsung terhadap proses seperti kualitas fokus sinar, sistem pemosisian dan waktu set up (Apostolos, dkk, 2012). Singh melakukan kajian total konsumsi energi pada proses gerinda melalui pengembangan model specific grinding energy. Singh menyatakan bahwa semakin keras material yang diproses akan secara signifikan meningkatkan nilai konsumsi energinya terutama jika kedalaman pemotongan diperbesar (Singh, dkk, 2012). Pada tahun 2011, Mori menyatakan bahwa produsen mesin perkakas dapat berkontribusi terhadap permasalahan efisiensi energi mesin melalui modifikasi fungsi lanjutan pada mesin perkakas. Beberapa modifikasi tersebut diantaranya adalah modifikasi fungsi parameter pemotongan, sinkronisasi percepatan spindle dan umpan baliknya serta termasuk penyempurnaan sistem pengaturan percepatan (Mori, dkk, 2011). Balogun menyajikan model kebutuhan energi listrik untuk setiap fase penggunaan mesin perkakas, validasi eksperimen dan pengukuran konsumsi energi dilakukan pada obyek mesin perkakas untuk mengetahui nilai konsumsi energi unit auxiliary dan unit utama mesin, terutama saat mesin start up dan machine ready, dan saat mesin melakukan pemotongan (Balogun \& Mativenga, 2013). Kajian efisiensi energi pada 
proses gerinda dilakukan Li dan tim pada tahun 2012 melalui pendekatan ekoefisiensi untuk mengevaluasi keterkaitan antara parameter proses, konsumsi energi dan sumber daya serta kinerja kualitas (Li, dkk, 2012). Pada tahun 2015, Li dan tim melakukan kajian empiris pada pemesinan electrical discharge machine (EDM) untuk mengkarakterisasi efisiensi energi proses EDM dan mengungkapkan keterkaitan antara SEC dan MRR pada pemesinan EDM (Li \& Kara, 2015).

Kajian terhadap topik penelitian efisiensi energi pada proses manufaktur dengan obyek mesin perkakas, pada umumnya fokus kajian adalah pada pertimbangan parameter pemesinan, faktor capaian kualitas produk, pemetaan konsumsi energi pada setiap fase operasi penggunaan mesin, hingga penyempurnaan fungsi mesin oleh machine builder. Pada topik penelitian ini belum dilakukan kajian kinerja efisiensi energi yang mempertimbangkan aspek kerugian mekanik karena faktor kondisi ketidakselarasan sistem transmisi mesin perkakas.

Penelitian ini bertujuan untuk melakukan kajian evaluasi efisiensi energi mesin bubut pada kondisi sistem transmisi pulley-belt mesin yang selaras dan tidak selaras. Kajian ini menggunakan metoda penilaian indikasi specific energy consumption (SEC) dari proses pemesinan bubut. Obyek studi pada kasus penelitian ini adalah lima buah mesin bubut uji yang berkapasitas daya medium yaitu antara 1 hingga $11 \mathrm{~kW}$, material benda kerja jenis baja karbon rendah St37 dan alat potong carbide. Proses pengujian selain mempertimbangkan parameter uji pemesinan juga mempertimbangkan kondisi sistem transmisi pulley-belt mesin yang selaras dan tidak selaras untuk melihat besar pengaruhnya terhadap kinerja efisiensi energi mesin perkakas.

Terdapat beberapa metoda untuk mengukur tingkat konsumsi energi pada suatu mesin. Proses yang paling umum dilakukan yaitu dengan menentukan daya pemotongan secara empiris dari hasil pengukuran gaya tangensial yang terjadi pada saat pemotongan menggunakan alat uji dinamometer. Namun dengan keterbatasan alat uji dan pengadaan yang sulit dilakukan, maka penelitian dilakukan dengan metoda yang lebih sederhana dan mudah diterapkan di industri. Metoda yang dapat dilakukan yaitu dengan metodologi penilaian mesin menggunakan specific energy consumption (SEC).

\subsection{Specific Energy Consumption (SEC)}

SEC merupakan perbandingan antara total energi yang dikonsumsi dengan suatu aspek fisik yang ditinjau. Pada proses pemesinan, SEC didefinisikan sebagai sejumlah energi yang diperlukan untuk memotong satu unit volume material (Zhang, dkk, 2017). Pada proses bubut, SEC dapat dihitung berdasarkan perbandingan antara total daya yang dikonsumsi dengan kecepatan pembentukan geram atau Material Removal Rate (MRR). Hal ini ditunjukkan pada Persamaan (1) dan Persamaan (2).

$$
\begin{aligned}
& S E C=\frac{\text { Netinputelectricalenergy }(\text { Watt })}{\text { MaterialRemovalRate }(\mathrm{cm} 3 / \mathrm{s})} \\
& M R R=f . V_{c} \cdot \text { doc }
\end{aligned}
$$

Pada Gambar 2 ditunjukkan skema proses pemesinan pada mesin bubut yang menyebabkan terjadinya pemotongan benda kerja sebesar nilai MRR. MRR $\left[\mathrm{mm}^{3} / \mathrm{s}\right]$ adalah nilai volume yang dipotong dari proses pemesinan selama durasi waktu tertentu. Nilai MRR dapat ditentukan berdasarkan besarnya gerak pemakanan atau feeding (f) $[\mathrm{mm} / \mathrm{rev}]$, kecepatan potong atau velocity cutting (Vc) $[\mathrm{mm} / \mathrm{s}]$ dan kedalaman pemotongan atau depth of cut $(\mathrm{doc})[\mathrm{mm}]$ (Groover, 2016). 


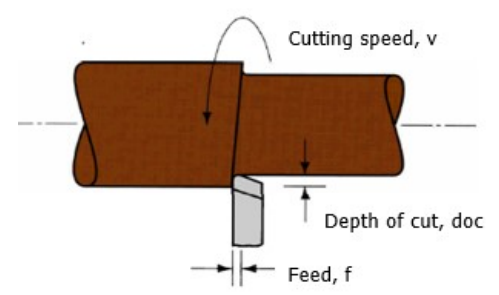

\section{Gambar 2. Proses Pemesinan pada Mesin Bubut (Groover, 2016)}

Li dkk mengidentifikasi faktor-faktor yang berpengaruh terhadap nilai SEC pada proses bubut, dan mengklasifikasikan level kontribusi pengaruhnya dalam empat kelompok faktor, yaitu design factors, screening factors, held-constant factors dan nuisance factors. Jenis material, kecepatan potong, kedalaman pemotongan dan gerak makan dikategorikan dalam kelompok design factor yang secara siginifikan berpengaruh terhadap nilai SEC (Li, 2015).

Model SEC dapat diturunkan berdasarkan model konsumsi energi. Pada Gambar 3 ditampilkan model konsumsi energi yang dikategorikan menjadi dua kelompok, yaitu energi yang diperlukan mesin dalam keadaan ready (auxiliary equipment \& infrastructure) dan sejumlah energi tambahan (physics) yang jumlahnya proporsional dengan jumlah material yang diproses.

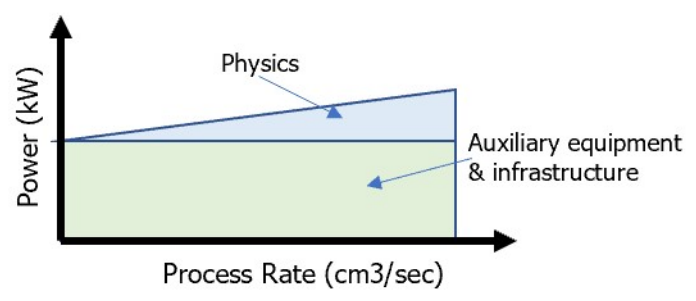

\section{Gambar 3. Model Konsumsi Energi dan SEC untuk Mesin yang Digunakan pada Proses Manufaktur (Zhou, dkk, 2016)}

Pada Persamaan (3) ditunjukkan perhitungan nilai konsumsi total daya mesin yang ditentukan oleh daya idle dan daya proses $(k \dot{v})$. P adalah total konsumsi daya dalam $\mathrm{kW}$, Po ialah daya idle dalam $\mathrm{kW}, \mathrm{k}$ merupakan konstanta proses dalam $\mathrm{kJ} / \mathrm{cm}^{3}$, dan $\mathrm{v}$ yaitu rate of material processing dalam $\mathrm{cm}^{3} / \mathrm{s}$.

$$
P=P_{0}+k \dot{\mathrm{V}}
$$

Setiap mesin perkakas memiliki nilai machine tool specific coefficients yang berbeda, pada Persamaan (4) ditampilkan sebuah perhitungan pendekatan inverse model untuk menggambarkan hubungan antara SEC dengan MRR (Kara \& Li, 2011).

$$
S F C=C_{O}+\frac{C_{1}}{M R K}
$$

Total konsumsi daya mesin terbagi menjadi standby power, spindle power dan additional requirement power seperti yang diperlihatkan pada Persamaan (5). Nilai spindle power dinyatakan sebagai konstanta $k_{1} \mathrm{n}+\mathrm{b}$, dimana $\mathrm{n}$ ialah kecepatan spindle, b dan $k_{1}$ adalah specific coefficient dari spindle motor, dan $k_{0}$ merupakan konstanta spesifik energi. Pada Persamaan (6) ditunjukkan model SEC yang diturunkan dari Persamaan (4). 


$$
\begin{aligned}
& P_{\text {normal }}=P_{\text {staindby }}+k_{1} n+b+k_{0} M R R \\
& S E C=\frac{P_{\text {normal }}}{M R R}=k_{0}+\frac{k_{1} n}{M R R}+\frac{k_{2}}{M R R}
\end{aligned}
$$

\subsection{Efisiensi Energi Pada Proses Bubut.}

Efisiensi energi pada proses bubut didefinisikan berdasarkan perbandingan antara daya pemotongan dengan daya total yang dikonsumsi mesin. Terdapat tiga komponen gaya pada proses pemotongan bubut, yaitu gaya potong tangensial $\left(F_{v}\right)$, aksial $\left(F_{a}\right)$ dan radial $\left(F_{r}\right)$. Gaya potong tangensial $\left(F_{v}\right)$ berpengaruh besar terhadap daya pemotongan, dikarenakan besarnya gerak dan gaya makan aksial $\left(\mathrm{F}_{\mathrm{a}}\right)$ lebih rendah dibandingkan dengan gerak dan gaya potong $\left(F_{v}\right)$. Pada Persamaan (7) ditampilkan perhitungan besar daya pemotongan $N_{c}$ $[\mathrm{kW}]$, dimana $\mathrm{F}_{\mathrm{v}}[\mathrm{N}]$ adalah gaya tangensial dan $\mathrm{v}$ ialah kecepatan potong $[\mathrm{m} / \mathrm{min}]$.

$$
\begin{aligned}
& N_{c}=\frac{F_{v} \cdot v}{60.000} ; k W \\
& \eta_{c}=\frac{N_{c}}{N_{m c}} 100 \%
\end{aligned}
$$

Efisiensi pemesinan $\left(\eta_{\mathrm{c}}\right.$ ) dihitung menggunakan Persamaan (8). $\mathrm{N}_{\mathrm{mc}}$ adalah daya total mesin yang diukur dengan menggunakan wattmeter. Daya total mesin merupakan penjumlahan antara daya potong, daya idle dan daya yang hilang saat proses pemesinan berlangsung.

Pada Persamaan (9) ditunjukkan besarnya efisiensi pemesinan juga dapat dihitung melalui pendekatan yang berbeda yaitu dengan menggunakan nilai dari specific energy consumption (SEC) dan specific cutting energy (SCE).

$$
\eta_{c}=\frac{N_{c} / M R R}{N_{m c} / M R R}=\frac{S C E}{S E C} 100 \%
$$

\subsection{Specific Cutting Energy (SCE)}

Jumlah konsumsi energi yang diperlukan untuk memotong satu unit volume material benda kerja dinyatakan sebagai specific cutting energy (SCE) atau ks. Menurut Riggatti (2013), ks merupakan kuantitas intensif yang mewakili ketahanan pemotongan material benda kerja, yang ditentukan oleh jenis material, geometri dan jenis pahat, serta parameter pemotongan (Rigatti, dkk, 2013). Pada Persamaan (10) ditunjukkan perhitungan ks yang ditentukan secara teoretis berdasarkan perbandingan antara daya pemotongan dengan MRR. Dimana $F_{v}$ adalah gaya tangensial [Newton], $v$ ialah kecepatan potong [m/menit] dan nilai ks dapat diperoleh pada katalog manual pembuat alat potong.

$$
k_{s}=\frac{F_{v} \cdot v}{M R R}
$$

\section{METODE PENELITIAN}

Sesuai dengan konsep penilaian kinerja efisiensi energi mesin bubut dicapai dengan mencermati indikator SEC. Metoda penilaian ini lebih sederhana dan mudah diterapkan di industri jika dibandingkan dengan menggunakan indikator efisiensi energi, karena pada metoda SEC besar gaya pemotongan tidak perlu diukur (menggunakan dinamometer). Penilaian dilakukan melalui perbandingan antara efisiensi aktual dengan nilai referensi 
efisiensi untuk menilai prosesnya. Penelitian dilakukan dalam beberapa tahapan, yaitu mulai dari (i)penentuan obyek mesin uji dan parameter ujinya, (ii)pengujian dan pengambilan data, (iii)pengolahan data untuk mendapatkan nilai referensi, hingga (iv)penilaian skor SEC setiap mesin uji.

\subsection{Penentuan Obyek Mesin Uji Dan Parameter Uji}

Klasifikasi daya motor penggerak mesin perkakas dikategorikan dalam tiga kelompok yaitu: (1) Low dutty machine yang menggunakan daya penggerak kurang dari 1,1 kW, (2) Medium dutty machine dengan daya penggerak dari $1,1 \mathrm{~kW}$ hingga $11 \mathrm{~kW}$, dan (3) Heavy dutty machine yang daya motor penggeraknya diatas $11 \mathrm{~kW}$. Pada Gambar 4 ditampilkan obyek uji penelitian berupa mesin bubut berkapasitas medium. Obyek uji berjumlah lima buah mesin bubut yang terdiri dari dua buah mesin bubut Weiler, dua buah mesin bubut Grazioli Fortuna dan satu buah mesin bubut Grazioli Dania yang ada di PT.XYZ. Pada Gambar 4a diperlihatkan gambar mesin bubut Weiler dengan kapasitas daya sebesar 1,6 kW, mesin bubut Grazioli Fortuna berkapasitas daya 3 kW ditampilkan pada Gambar 4b dan pada Gambar 4c ditunjukkan gambar mesin bubut Grazioli Dania yang memiliki kapasitas daya sebesar $4 \mathrm{~kW}$.

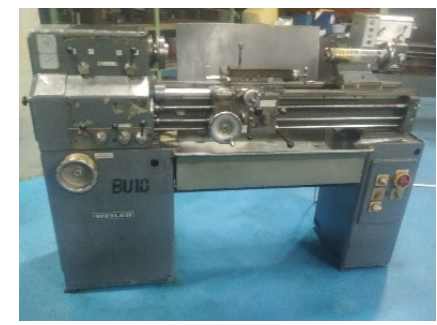

(a)

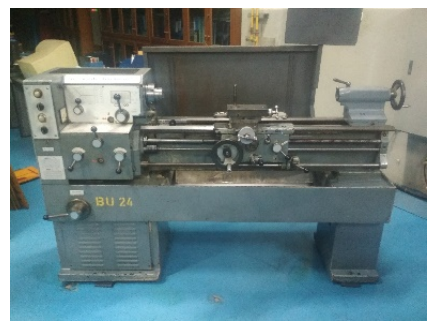

(b)

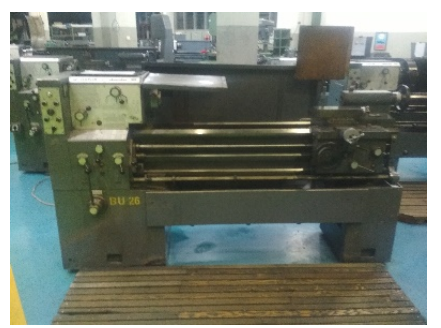

(c)

Gambar 4. Obyek Mesin Uji. (a) Weller, (b) Grazioli Fortuna dan (c) Grazioli Dania

Material benda kerja yang digunakan pada penelitian ini adalah baja karbon rendah St37 yang termasuk ke dalam grup material PI. Material benda uji berbentuk selinder dengan ukuran diameter $45 \mathrm{~mm}$ dan Panjang $150 \mathrm{~mm}$. Pada Tabel 1 ditunjukkan beberapa sifat mekanik dari material ini.

Tabel 1. Sifat Material St 37

\begin{tabular}{|c|c|}
\hline Sifat mekanik material & Nilai \\
\hline Massa jenis & $7860 \mathrm{~kg} / \mathrm{m}^{3}$ \\
\hline Tegangan yield & $260 \mathrm{~N} / \mathrm{mm}^{2}$ \\
\hline Tegangan ultimate & $370 \mathrm{~N} / \mathrm{mm}^{2}$ \\
\hline Kekerasan material & $98 \mathrm{HRB}$ \\
\hline
\end{tabular}

Alat potong yang digunakan adalah carbida insert SNMG 120404E-FM dengan grade T9135 yang dapat digunakan untuk memotong material PI - PII (Pramet, 2016).

Pemilihan parameter pemesinan disesuaikan dengan jenis alat potong yang digunakan. Pada penelitian ini, feeding (f) dan kedalaman pemotongan (doc) berada pada kondisi yang variatif sesuai dengan range yang telah direkomendasikan supplier alat potong. Hal ini dilakukan karena variasi satu dan/atau dua dari ketiga parameter pemotongan (kecepatan pemotongan, kedalaman pemotongan dan feeding) akan menyebabkan perubahan SEC yang cukup signifikan sehingga variabel lain perlu dipertahankan secara konstan. Feeding (f) dan kedalaman pemotongan (doc) dipilih sebagai parameter yang divariasikan, karena fitur 
pengaturan dua parameter tersebut available pada mesin bubut. Berdasarkan katalog Pramet, kedalaman potong yang dipilih untuk grup material PI (St37) adalah 0,5 - $3 \mathrm{~mm}$, feeding adalah $0,10-0,35 \mathrm{~mm} / \mathrm{rev}$ dan untuk kecepatan pemotongan yang diijinkan sesuai grade tool yang digunakan yaitu $230 \mathrm{~mm} / \mathrm{min}$ (Pramet, 2016). Pada Tabel 2 ditampilkan variasi nilai parameter pemesinan yang digunakan pada penelitian.

Tabel 2. Variasi Nilai Parameter Pemesinan

\begin{tabular}{|c|c|c|c|c|c|c|c|}
\hline No & $\begin{array}{c}\text { Diameter } \\
\text { benda } \\
\text { kerja } \\
(\mathbf{m m})\end{array}$ & $\begin{array}{c}\text { Putaran } \\
\text { (rpm) }\end{array}$ & $\begin{array}{c}\text { Putaran } \\
\text { aktual } \\
\text { (rpm) }\end{array}$ & $\begin{array}{l}\text { Kecepatan } \\
\text { potong } \\
(\mathrm{m} / \mathrm{min})\end{array}$ & $\begin{array}{c}\text { Kedalaman } \\
\text { pemotongan } \\
(\mathbf{m m})\end{array}$ & $\begin{array}{c}\text { Feeding } \\
\text { (mm/rev) }\end{array}$ & $\begin{array}{c}\text { Debit } \\
\text { pemotongan } \\
\left(\mathrm{cm}^{3} / \mathrm{s}\right)\end{array}$ \\
\hline 1 & 44,50 & 1646 & 1500 & 230 & 0,76 & 0,10 & 0,29 \\
\hline 2 & 42,99 & 1704 & 1500 & 230 & 0,89 & 0,10 & 0,34 \\
\hline 3 & 41,21 & 1777 & 1500 & 230 & 1,02 & 0,10 & 0,39 \\
\hline 4 & 39,18 & 1870 & 1500 & 230 & 0,75 & 0,15 & 0,43 \\
\hline 5 & 37,68 & 1944 & 2000 & 230 & 0,89 & 0,15 & 0,51 \\
\hline 6 & 35,91 & 2040 & 2000 & 230 & 1,01 & 0,15 & 0,58 \\
\hline 7 & 33,89 & 2161 & 2000 & 230 & 1,10 & 0,15 & 0,63 \\
\hline 8 & 31,70 & 2311 & 2000 & 230 & 0,97 & 0,20 & 0,74 \\
\hline 9 & 29,77 & 2461 & 2000 & 230 & 1,07 & 0,20 & 0,82 \\
\hline 10 & 27,63 & 2651 & 2000 & 230 & 1,24 & 0,20 & 0,95 \\
\hline 11 & 25,15 & 2912 & 2000 & 230 & 1,33 & 0,20 & 1,02 \\
\hline 12 & 44,50 & 1646 & 1500 & 230 & 1,17 & 0,25 & 1,12 \\
\hline 13 & 42,16 & 1737 & 1500 & 230 & 1,26 & 0,25 & 1,21 \\
\hline 14 & 39,64 & 1848 & 1500 & 230 & 1,35 & 0,25 & 1,29 \\
\hline 15 & 36,95 & 1983 & 2000 & 230 & 1,46 & 0,25 & 1,40 \\
\hline 16 & 34,02 & 2153 & 2000 & 230 & 1,31 & 0,30 & 1,51 \\
\hline 17 & 31,40 & 2333 & 2000 & 230 & 1,39 & 0,30 & 1,60 \\
\hline 18 & 28,61 & 2560 & 2000 & 230 & 1,50 & 0,30 & 1,72 \\
\hline 19 & 25,62 & 2859 & 2000 & 230 & 1,58 & 0,30 & 1,82 \\
\hline 20 & 22,46 & 3262 & 2000 & 230 & 1,67 & 0,30 & 1,92 \\
\hline
\end{tabular}

Untuk mengetahui pengaruh kondisi keselarasan sistem transmisi sabuk dan puli terhadap efisiensi energi mesin, pengujian pemotongan dilakukan dalam dua kondisi sistem transmisi, yaitu pada kondisi selaras dan tidak selaras. Proses ketidakselarasan sistem transmisi diberikan dengan penyimpangan defleksi dan penyimpangan kesejajaran puli di luar toleransi yang diijinkan. Besar penyimpangan defleksi yang dilonggarkan yaitu $50 \%$ dari dari nilai defleksi yang diijinkan (Optibelt, 2015) (Budynas \& Nisbett, 2011). Pada Tabel 3 ditampilkan besar nilai ketidakselarasan untuk setiap obyek mesin uji.

Tabel 3. Nilai Ketidakselarasan yang Diberikan

\begin{tabular}{|c|c|c|c|c|}
\hline \multirow{2}{*}{ No } & Nama mesin & \multicolumn{3}{|c|}{ Kondisi } \\
\cline { 3 - 5 } & & Defleksi (mm) & Parallel (mm) & Angular ( $\left.{ }^{\circ}\right)$ \\
\hline 1 & Weiler (1) & 18 & 0,9 & 0,5 \\
\hline 2 & Weiler (2) & 18 & 0,9 & 0,5 \\
\hline 3 & Grazioli Dania 180 (1) & 11 & 0,55 & 0,3 \\
\hline 4 & Grazioli Dania 180 (2) & 11 & 0,55 & 0,3 \\
\hline 5 & Grazioli Fortuna 150 & 9 & 0,55 & 0,3 \\
\hline
\end{tabular}

\subsection{Pengujian}

Pengujian pemotongan dilakukan dengan variasi nilai parameter pemesinan sesuai nilai pada Tabel 2 dan variasi nilai ketidakselarasan seperti pada Tabel 3. Saat pemotongan 
berlangsung total konsumsi daya listrik mesin diukur menggunakan harmonic power analyzer fluke 43 B. Daya total mesin merupakan penjumlahan dari daya potong, daya idle dan daya yang hilang saat proses pemesinan berlangsung. Pada Gambar 5a ditampilkan perangkat power analyzer yang digunakan untuk mengukur nilai total konsumsi daya listrik mesin. Pada Gambar 5b ditunjukkan skema rangkaian pengukurannya, dimana nilai konsumsi arus diukur menggunakan probe 2 dan pengukuran nilai tegangan menggunakan probe 1 dan probe Com.

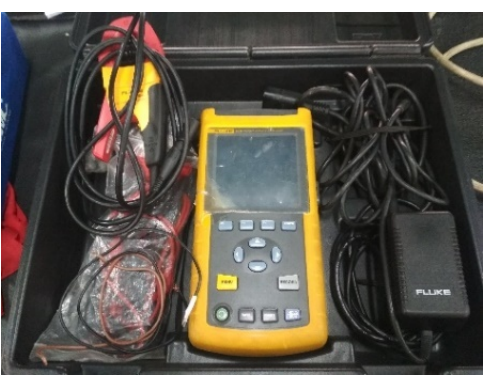

(a)

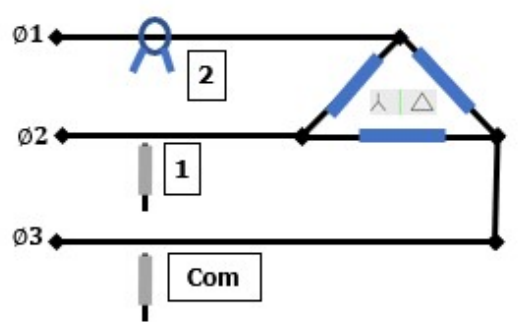

(b)

Gambar 5. (a) Power Analyzer, (b) Rangkaian Listrik (Fluke, 2012)

\subsection{Pengolahan Data}

Data konsumsi daya total hasil pengukuran dikumpulkan dan diolah lebih lanjut menggunakan Persamaan (1) dan Persamaan (2) yang membandingkan hasil pengukuran (power analyzer) konsumsi daya aktual terhadap nilai material removal rate (MRR), sehingga diperoleh data specific energy consumption (SEC) pada setiap nilai kondisi pemotongan. Sebelum melakukan analisa, nilai minimum pada SEC ditentukan terlebih dahulu melalui modifikasi nilai SEC setiap kondisi menjadi 1/SEC. Kemudian data nilai MRR dan SEC yang dihasilkan dianalisis dengan metode data envelopment analysis (DEA) menggunakan software max DEA untuk menentukan harga referensi.

Model DEA yang digunakan pada penelitian evaluasi efisiensi energi pada proses bubut ini menggunakan model variable return scale (VRS), karena model ini dapat mengakomodir suatu proses yang tidak selalu berjalan pada kondisi yang optimum pada seluruh rentang masukan dan keluarannya (Huguenin, 2012).

\subsection{Proses Penilaian SEC Obyek Mesin Uji}

Logika proses penilaian obyek mesin pada metodologi penelitian adalah membandingkan nilai SEC suatu proses yang dinilai terhadap harga referensi. Skor nilai SEC setiap mesin menunjukkan jumlah energi yang perlu diturunkan agar proses pemesinan pada mesin tersebut lebih efisien. Jika semakin pendek jarak nilai SEC terhadap garis referensi, maka semakin efisien penggunaan energi pada mesin tersebut.

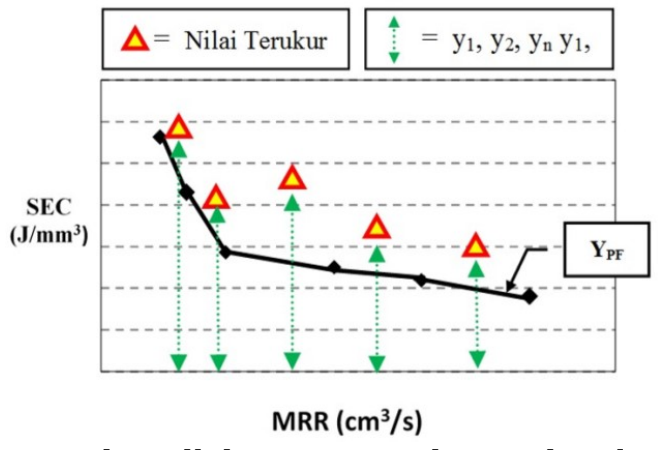

Gambar 6. Ilustrasi Penilaian Konsumsi Energi pada Proses Bubut 
Proses penilaian diilustrasikan pada Gambar 6 . Harga referensi pada gambar terdiri dari 6 data dengan 5 segmen garis. Penilaian berbasis skor digunakan sebagai skala pembanding. Nilai skor penurunan energi pada proses pemotongan tertentu dapat dihitung menggunakan Persamaan (11), dimana $Y_{i}$ ialah besarnya SEC pada MRR ke-i, Y PFi merupakan nilai harga referensi pada MRR ke-i, dan $\mathrm{n}$ adalah jumlah pengujian. Skor ini menggambarkan jumlah energi yang perlu diturunkan agar proses dapat mencapai kondisi yang efisien. Pada proses bubut efisiensi akan meningkat sesuai dengan peningkatan beban hingga batas tertentu.

$$
\begin{aligned}
& \text { Nilai penurunan energi }=\frac{Y i-Y p f i}{Y i} .100 \% \\
& \text { Rata }- \text { rata penurunan energi }=\frac{\sum_{i=1}^{n} \text { skor } i}{n} .100 \%
\end{aligned}
$$

Evaluasi dilakukan pada beberapa variasi pemotongan untuk menggambarkan kinerja penggunaan energi mesin tersebut. Penilaian akhir (rata-rata konsumsi energi) dilakukan berdasarkan nilai-nilai konsumsi energi yang diperoleh dari beberapa pengujian pada rentang MRR tertentu. Rata-rata penurunan energi yang terjadi dihitung dengan menggunakan Persamaan (12) dan $n$ merupakan jumlah pengujian yang dilakukan. Jumlah pengujian (n) minimal dalam proses penilaian harus sesuai dengan jumlah segmen garis yang ada pada harga referensi, sehingga terdapat perwakilan data untuk setiap segmen garis. Jika semakin banyak jumlah pengujian yang dilakukan, maka semakin akurat penilaian yang dihasilkan. Semakin rendah rata-rata konsumsi energi yang dihasilkan, semakin dekat dengan harga referensi dan semakin baik kinerja penggunaan energi pada mesin tersebut.

\section{HASIL DAN PEMBAHASAN}

Hasil assessment menunjukkan bahwa mesin dengan daya motor yang sama dapat memiliki nilai konsumsi daya listrik yang berbeda walaupun pada proses pemotongan dengan MRR yang sama. Selain itu kondisi keselarasan sistem transmisi memberi pengaruh terhadap konsumsi daya mesin. Hal ini disebabkan karena adanya rugi-rugi pada mekanik sistem transmisi dan motor listrik yang digunakan.

Berdasarkan kajian perbandingan rerata presentasi peningkatan konsumsi energi akibat ketidakselarasan pada Gambar 7, diperoleh bahwa pada mesin Weiler 1 terjadi peningkatan sebesar 7,25\%, dan pada mesin Weiler 2 menunjukkan nilai yang relatif lebih rendah yaitu sebesar $7,75 \%$. Perbedaan nilai peningkatan konsumsi energi listrik pada mesin Weiler 1 dan mesin Weiler 2 adalah disebabkan adanya kualitas komponen puli dan belt pada mesin Weiler 1 yang kurang baik, sehingga mesin Weiler 1 mengalami peningkatan konsumsi daya listrik yang lebih tinggi ketika diuji pada kondisi penyimpangan ketidakselarasan yang sama.

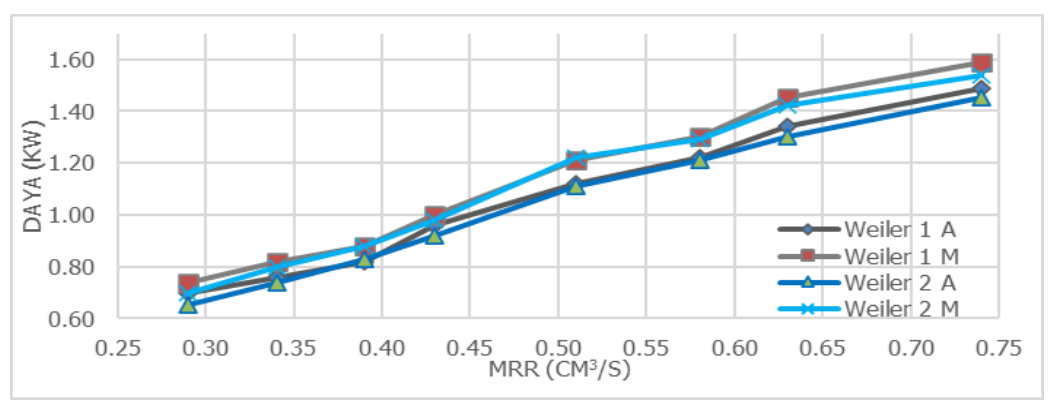

\section{Gambar 7. Grafik Konsumsi Daya Listrik Mesin Weiler1 dan Weiler2 pada Proses Pemotongan dengan Berbagai Nilai MRR}


Pada Gambar 7 diilustrasikan konsumsi daya listrik mesin Weiler 1 dan 2 pada proses pemotongan dengan berbagai nilai MRR dan pada dua kondisi sistem transmisi yaitu kondisi A (alignment atau selaras) dan kondisi M (misalignment atau tidak selaras). Data nilai konsumsi daya listrik pada proses pemotongan dihitung menggunakan Persamaan 1 dengan membandingkan daya listrik pada proses pemotongan yang diukur terhadap nilai MRR untuk menghasilkan nilai SEC pada setiap kondisi pemotongan. Berikut contoh perhitungan nilai SEC pada mesin Weiler 1 pada kondisi selaras dengan nilai MRR 0,29 menggunakan Persamaan(1).

$$
S E C=\frac{\text { Net input electrical energy }(\text { Watt })}{\text { Material Removal Rate }\left(\mathrm{cm}^{3} / \mathrm{s}\right)}=\frac{0.7}{0,29}=2,41 \mathrm{~kJ} / \mathrm{cm}^{3}
$$

Pada Tabel 4 ditunjukkan data perhitungan setiap nilai SEC untuk berbagai vareasi nilai MRR percobaan pemotongan dari $0,29 \mathrm{~cm}^{3} / \mathrm{s}$ hingga $0,74 \mathrm{~cm}^{3} / \mathrm{s}$ pada mesin Weiler dengan kondisi sistem transmisi selaras.

Tabel 4. Hasil Nilai SEC pada Mesin Weiler1 Kondisi Selaras

\begin{tabular}{|c|c|c|c|c|c|c|c|}
\hline No & $\begin{array}{c}\text { Diameter benda } \\
\text { kerja ( } \mathbf{m m})\end{array}$ & $\begin{array}{c}\mathrm{N} \\
(\mathbf{r p m})\end{array}$ & $\begin{array}{c}\text { MRR } \\
\left(\mathrm{cm}^{3} / \mathrm{s}\right)\end{array}$ & $\begin{array}{c}\text { Daya listrik } \\
\text { pemotongan }(\mathrm{kW})\end{array}$ & $\begin{array}{c}\text { SEC } \\
\left(\mathrm{kJ} / \mathrm{cm}^{3}\right)\end{array}$ & 1/SEC & DMU \\
\hline 1 & 44,50 & 1500 & 0,29 & 0,70 & 2,41 & 0,41 & $A$ \\
\hline 2 & 42,99 & 1500 & 0,34 & 0,76 & 2,24 & 0,45 & B \\
\hline 3 & 41,21 & 1500 & 0,39 & 0,82 & 2,10 & 0,48 & $\mathrm{C}$ \\
\hline 4 & 39,18 & 1500 & 0,43 & 0,96 & 2,23 & 0,45 & $\mathrm{D}$ \\
\hline 5 & 37,68 & 2000 & 0,51 & 1,12 & 2,20 & 0,46 & $E$ \\
\hline 6 & 35,91 & 2000 & 0,58 & 1,22 & 2,10 & 0,48 & $\mathrm{~F}$ \\
\hline 7 & 33,89 & 2000 & 0,63 & 1,34 & 2,13 & 0,47 & $\mathrm{G}$ \\
\hline 8 & 31,70 & 2000 & 0,74 & 1,49 & 2,01 & 0,50 & $\mathrm{H}$ \\
\hline
\end{tabular}

Hasil analisis DEA mendapatkan nilai proyeksi dari MRR dan 1/SEC. Nilai proyeksi ini membentuk beberapa persamaan garis yang saling terhubung satu sama lain. Persamaan garis tersebut menjadi harga referensi sebagai nilai optimum pada proses yang dilakukan (Huguenin, 2012).

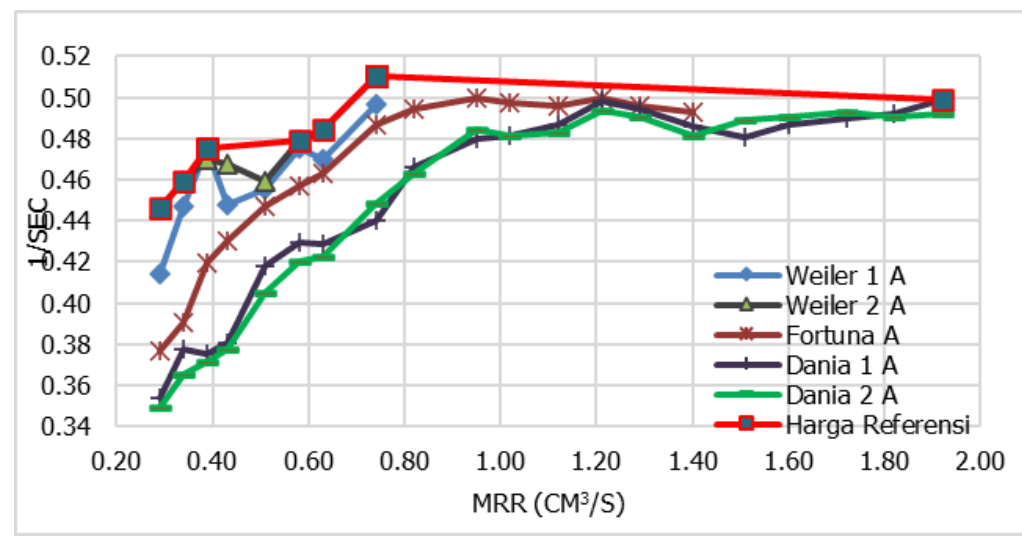

Gambar 8. Grafik Harga Referensi Terhadap Nilai 1/SEC dengan Variasi MRR pada Kondisi Selaras

Harga referensi dari MRR dan 1/SEC dapat ditentukan secara langsung menggunakan fitur scatter $x-y$ pada microsoft excell dengan nilai proyeksi MRR sebagai $x$ dan nilai proyeksi 1/SEC sebagai y. Pada Gambar 8 ditunjukkan grafik harga referensi terhadap nilai 1/SEC dengan variasi MRR pada kondisi selaras untuk percobaan pemotongan di lima obyek mesin 
uji. Pada Gambar 9 ditampilkan grafik harga referensi terhadap nilai $1 /$ SEC dengan variasi MRR di setiap mesin uji pada kondisi tidak selaras.

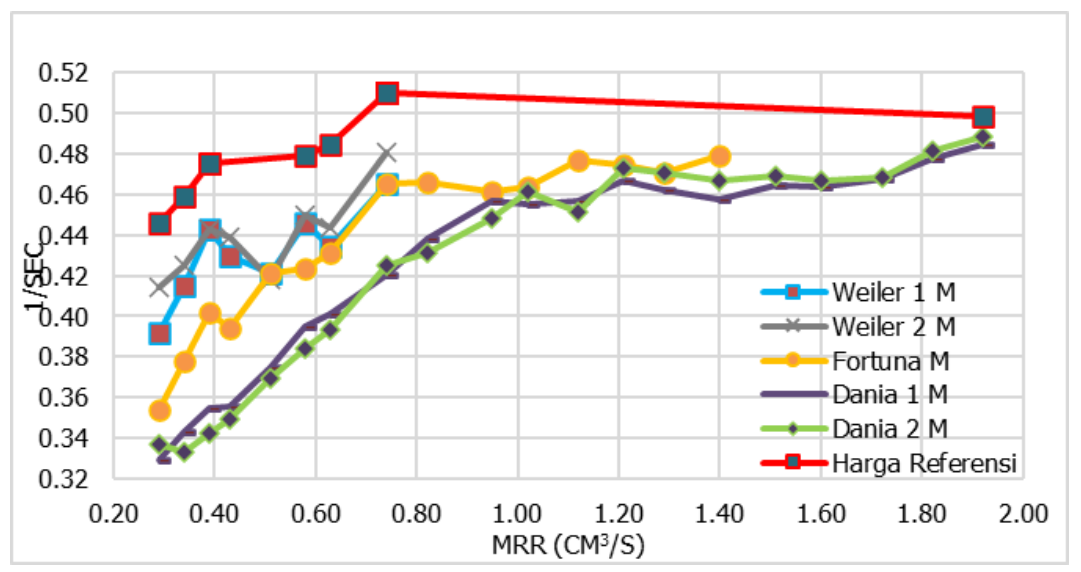

\section{Gambar 9. Grafik Harga Referensi Terhadap Nilai 1/SEC dengan Variasi MRR pada Kondisi tidak Selaras}

Untuk menentukan nilai referensi pada grafik SEC - MRR dilakukan perubahan pada nilai proyeksi 1/SEC menjadi proyeksi SEC sehingga diperoleh harga referensi. Pada Gambar 10 ditampilkan grafik harga referensi untuk penilaian kinerja penggunaan energi pada proses bubut semua mesin uji dengan kondisi sistem transmisi pulley-belt yang selaras. Sedangkan pada Gambar 11 ditunjukkan grafik harga referensi untuk penilaian kinerja penggunaan energi pada proses bubut semua mesin uji dengan kondisi tidak selaras. Berdasarkan perbandingan penilaian kinerja penggunaan energi setiap mesin uji terhadap garis harga referensi pada kondisi selaras dan kondisi tidak selaras, diperoleh garis nilai penggunaan energi saat kondisi sistem transmisi tidak selaras mengalami peningkatan. Sebagai contoh garis penggunaan energi mesin Weiler 1 kondisi selaras (A) lebih dekat dengan garis harga referensi dibandingkan dengan garis penggunaan energi mesin Weiler 1 kondisi tidak selaras (M).

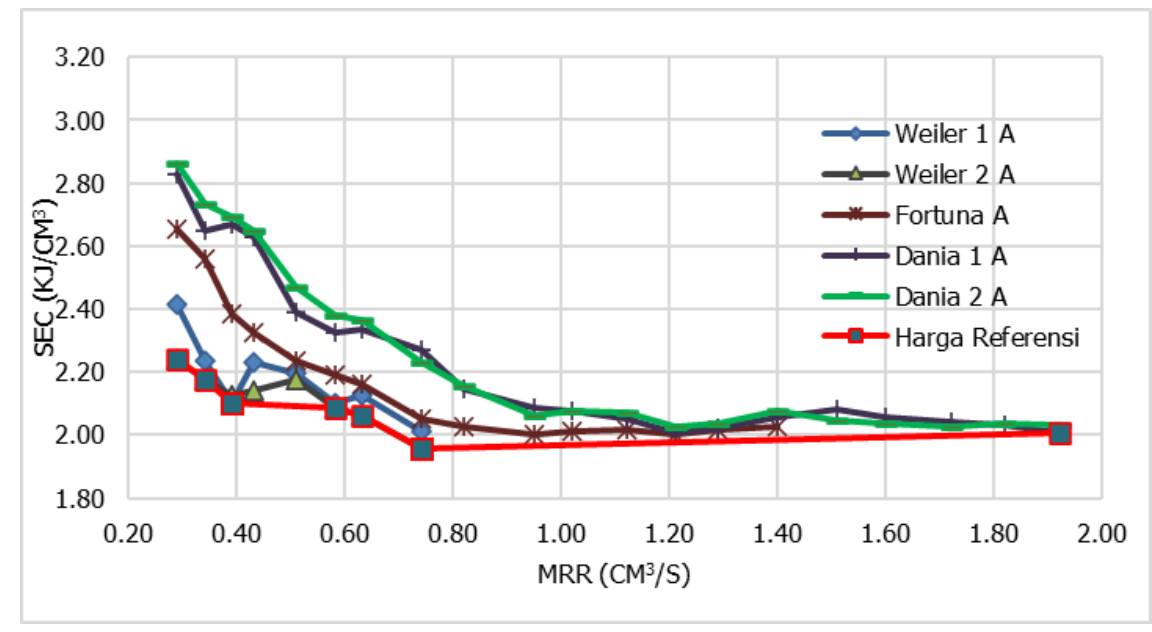

Gambar 10. Grafik Harga Referensi untuk Penilaian Kinerja Penggunaan Energi pada Proses Bubut Semua Mesin Uji dengan Kondisi Selaras 


\section{Harja $d k k$.}

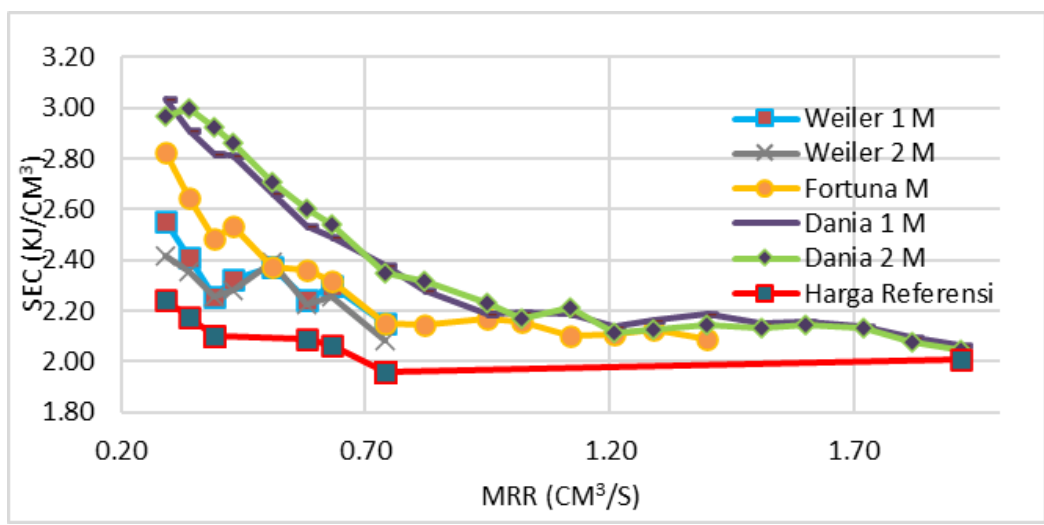

\section{Gambar 11. Grafik Harga Referensi untuk Penilaian Kinerja Penggunaan Energi pada Proses Bubut Semua Mesin Uji dengan Kondisi tidak Selaras}

Hasil analisis untuk harga referensi didapatkan persamaan garis pada setiap rentang MRR tertentu. Pada Tabel 5 ditampilkan rentang nilai MRR yang terbagi dalam beberapa segmen sesuai pengaturan parameter.

Tabel 5. Segmentasi Persamaan Garis Hasil DEA

\begin{tabular}{|c|c|c|c|}
\hline No & Segmen & Persamaan garis & Rentang MRR \\
\hline $1-2$ & $1 \mathrm{~s} / \mathrm{d} 2$ & $y=-1,298 x+2,617$ & $0,29-0,34$ \\
\hline $2-3$ & $2 \mathrm{~s} / \mathrm{d} 3$ & $y=-1,478 x+2,679$ & $0,34-0,39$ \\
\hline $3-4$ & $3 \mathrm{~s} / \mathrm{d} 6$ & $y=-0,086 x+2,136$ & $0,39-0,58$ \\
\hline $4-5$ & $6 \mathrm{~s} / \mathrm{d} 7$ & $y=-0,454 x+2,349$ & $0,58-0,63$ \\
\hline $5-6$ & $7 \mathrm{~s} / \mathrm{d} 8$ & $y=-0,946 x+2,659$ & $0,63-0,74$ \\
\hline $6-7$ & $8 \mathrm{~s} / \mathrm{d} 20$ & $y=0,039 x+1,931$ & $0,74-1,92$ \\
\hline
\end{tabular}

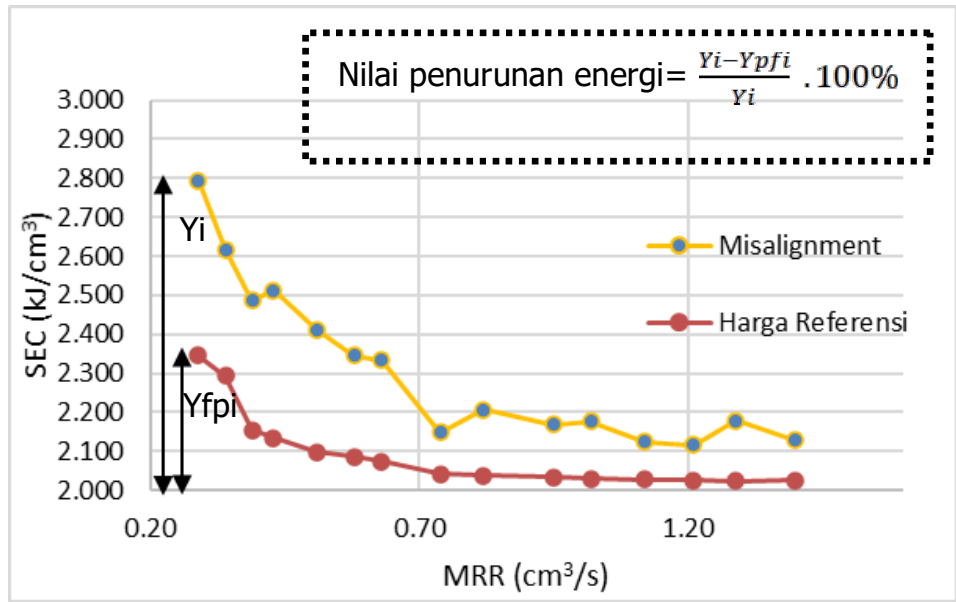

\section{Gambar 12. Ilustrasi Penilaian Konsumsi Energi pada Mesin Grazioli Fortuna 150 dengan Kondisi Selaras}

Proses penilaian untuk mesin Grazioli Dania dilakukan menggunakan harga referensi yang ditunjukkan pada Gambar 12. Perhitungan nilai penurunan energi menggunakan persamaan (11), data hasil penilaian tersebut dapat dilihat pada Tabel 6. Rata-rata penurunan energi untuk mesin Grazioli Dania adalah 9,23\%. Nilai penurunan energi ini bermakna bahwa untuk 
mencapai kondisi yang efisien diperlukan penurunan penggunaan energi rata-rata sebesar $9,23 \%$.

Tabel 6. Hasil Penilaian Penurunan Energi pada Mesin Grazioli Dania dengan Kondisi tidak Selaras

\begin{tabular}{|c|c|c|c|c|c|}
\hline No & $\begin{array}{c}\text { MRR } \\
\left(\mathbf{c m}^{\mathbf{3}} \mathbf{s} \mathbf{s}\right)\end{array}$ & Persamaan garis & Yi & Ypfi & $\begin{array}{c}\text { Penurunan } \\
\text { energi (\%) }\end{array}$ \\
\hline 1 & 0,29 & $y=-1,0141 x+2,6389$ & 2,793 & 2,345 & 16,04 \\
\hline 2 & 0,34 & $y=-2,8055 x+3,248$ & 2,618 & 2,294 & 12,36 \\
\hline 3 & 0,39 & $y=-0,4651 x+2,3352$ & 2,487 & 2,154 & 13,40 \\
\hline 4 & 0,43 & $y=-0,4651 x+2,3352$ & 2,512 & 2,135 & 15,00 \\
\hline 5 & 0,51 & $y=-0,169 x+2,1842$ & 2,412 & 2,098 & 13,01 \\
\hline 6 & 0,58 & $y=-0,169 x+2,1842$ & 2,345 & 2,086 & 11,04 \\
\hline 7 & 0,63 & $y=-0,169 x+2,1842$ & 2,333 & 2,073 & 11,16 \\
\hline 8 & 0,74 & $y=-0,2854 x+2,2517$ & 2,149 & 2,041 & 5,01 \\
\hline 9 & 0,82 & $y=-0,2854 x+2,2517$ & 2,207 & 2,038 & 7,67 \\
\hline 10 & 0,95 & $y=-0,2854 x+2,2517$ & 2,168 & 2,033 & 6,25 \\
\hline 11 & 1,02 & $y=-0,2854 x+2,2517$ & 2,176 & 2,030 & 6,73 \\
\hline 12 & 1,12 & $y=-0,2854 x+2,2517$ & 2,125 & 2,028 & 4,56 \\
\hline 13 & 1,21 & $y=-0,0192 x+2,048$ & 2,116 & 2,025 & 4,29 \\
\hline 14 & 1,29 & $y=0,0127 x+2,0069$ & 2,178 & 2,023 & 7,13 \\
\hline 15 & 1,4 & $y=0,0127 x+2,0069$ & 2,129 & 2,025 & 4,87 \\
\hline \multicolumn{5}{|c|}{ Rata-rata penurunan energi } \\
\hline
\end{tabular}

Setelah harga referensi diperoleh maka proses penilaian penurunan energi dapat dilakukan. Penilaian pada setiap mesin sesuai dengan Persamaan (10). Data SEC dibandingkan dengan harga referensi sesuai dengan range nilai MRR yang sama untuk menghasilkan nilai skor penurunan energi. Berdasarkan hasil perhitungan skor penurunan energi pada setiap mesin, didapatkan rata-rata skor penurunan energi pada semua mesin. Nilai ini dapat dijadikan acuan untuk mendapatkan nilai rata-rata penurunan energi pada semua mesin seperti pada Tabel 7.

Tabel 7. Rata-Rata Penurunan Energi pada Semua Mesin

\begin{tabular}{|c|c|c|c|}
\hline No & Mesin & Kondisi & Rata-rata penurunan energi [\%] \\
\hline \multirow{2}{*}{1} & \multirow{2}{*}{ Weiler 1 } & Selaras & 3,28 \\
\cline { 3 - 4 } & \multirow{2}{*}{2} & Tidak Selaras & 9,46 \\
\hline \multirow{2}{*}{3} & \multirow{2}{*}{ Weiler 2 } & Selaras & 1,17 \\
\cline { 3 - 4 } & \multirow{2}{*}{ Grazioli Fortuna } & Tidak Selaras & 7,71 \\
\cline { 3 - 4 } & \multirow{2}{*}{4} & Selaras & 5,66 \\
\hline \multirow{2}{*}{4} & Grazioli Dania 1 & Tidak Selaras & 9,23 \\
\cline { 3 - 4 } & \multirow{2}{*}{5} & Tidak Selaras & 8,42 \\
\hline \multirow{2}{*}{5} & \multirow{2}{*}{ Garzioli Dania 2 } & Selaras & 13,68 \\
\cline { 3 - 4 } & & Tidak Selaras & 8,96 \\
\hline \multicolumn{2}{|c|}{ Rata-rata penurunan energi semua mesin } & 13,85 \\
\hline
\end{tabular}

Rata-rata penurunan energi dari semua mesin dihitung dan dihasilkan nilai sebesar $8,31 \%$. Nilai ini dapat digunakan sebagai batas SEC sementara untuk mesin bubut yang diuji. Jika rata-rata penurunan energi dari suatu mesin mencapai ataupun kurang dari batas SEC maka dapat diasumsikan bahwa penggunaan energi pada mesin tersebut telah cukup baik. Berdasarkan Tabel 7 ditunjukkan bahwa mesin Weiler 1, Weiler 2, dan Grazioli Fortuna pada kondisi sistem transmisi selaras berada pada kondisi penggunaan energi yang baik. 
Harja $d k k$.

\section{KESIMPULAN}

Berdasarkan hasil penelitian evaluasi kinerja efisiensi energi mesin bubut melalui penilaian indikasi SEC dapat disimpulkan bahwa aspek kerugian mekanik faktor kondisi ketidakselarasan pada sistem transmisi pulley-belt mesin harus dipertimbangkan, karena mengakibatkan menurunnya kinerja efisiensi energi mesin bubut sebesar lebih dari $5 \%$. Penilaian skor penurunan energi pada beberapa obyek mesin uji diperoleh bahwa mesin Weiler 2 pada kondisi sistem transmisi yang selaras memiliki kinerja efisiensi energi terbaik dengan nilai skor sebesar $1.17 \%$, dan mesin Bubut Grazioli Dania 2 memiliki kinerja terburuk dengan nilai skor sebesar $8.96 \%$. Pada kondisi sistem transmisi yang tidak selaras, terjadi peningkatan nilai skor sebesar lebih dari $5 \%$, seperti pada mesin bubut Weiler 2 nilai skor meningkat menjadi $6,71 \%$ dari $1,17 \%$. Ketidakselarasan sistem transmisi memberi kontribusi terhadap inefisiensi energi mesin perkakas. Oleh karena itu, kegiatan

(maintenance) pemeriksaan dan perbaikan kondisi keselarasan sistem transmisi pulley-belt mesin perlu dilakukan secara rutin. Penelitian ini dapat dilanjutkan untuk mencermati pengaruh kondisi ketidakselarasan pada jenis sistem transmisi selain pulley-belt terhadap efisiensi energi mesin.

\section{DAFTAR RUJUKAN}

Apostolos, F., Alexios, P., Georgios, P., Panagiotis, S., \& George, C. (2013). Energy efficiency of manufacturing processes: A critical review. Procedia CIRP, 7, 628-633.

Apostolos, F., Panagiotis, S., Konstantinos, S., \& George, C. (2012). Energy Efficiency Assessment of Laser Drilling Process. Physics Procedia, 39, 776-783.

Balogun, V. A., \& Mativenga, P. T. (2013). Modelling of direct energy requirements in mechanical machining processes. Journal of Cleaner Production, 41, 179-186.

Budynas, R. G., \& Nisbett, J. K. (2011). Shigley's Mechanical Engineering Design (9th ed). New York: McGraw-Hill.

Fluke. (2012). Fluke 430 Series II Three-Phase Power Quality Analyzers. New York: Fluke Corporation.

Groover, M. (2016). Fundamentals of Modern Manufacturing (5th ed.). New Jersey: John Wiley \& Sons, Inc.

Huguenin, J. M. (2012). Data Envelopment Analysis (DEA) - A pedagogical guide for decision makers in the public sector. Lausanne: IDHEAP.

Kara, S., \& Li, W. (2011). Unit process energy consumption models for material removal processes. CIRP Annals - Manufacturing Technology, 60(1), 37-40.

Li, W. (2015). Efficiency of Manufacturing Processes. Switzerland: Springer International Publishing.

Li, W., \& Kara, S. (2015). Characterising energy efficiency of Electrical Discharge Machining (EDM) processes. Procedia CIRP, 29, 263-268.

Li, W., Winter, M., Kara, S., \& Herrmann, C. (2012). Eco-efficiency of manufacturing 
processes: A grinding case. CIRP Annals - Manufacturing Technology, 61(1), 59-62.

Mori, M., Fujishima, M., Inamasu, Y., \& Oda, Y. (2011). A study on energy efficiency improvement for machine tools. CIRP Annals - Manufacturing Technology, 60(1), 145-148.

Optibelt, G. (2015). Technical Manual V-Belt Drives. Hoxter: Arntz Optibelt Group.

Pramet. (2016). Cutting Tool New Catalog Pramet. Chesterfield: Dormer Pramet.

Rigatti, A. M. Y., Assis, C. L. F., Coelho, R. T., Jasinevicius, R. G., \& Rodrigues, A. R. (2013). Computational method for calculation of the specific cutting energy. 22nd International Congress of Mechanical Engineering, (pp. 2710-2715).

Singh, V., Rao, P. V., \& Ghosh, S. (2012). Development of specific grinding energy model. International Journal of Machine Tools and Manufacture, 60, 1-13.

Zhang, H., Deng, Z., Fu, Y., Wan, L., \& Liu, W. (2017). Optimization of process parameters for minimum energy consumption based on cutting specific energy consumption. Journal of Cleaner Production, 166, 1407-1414.

Zhou, L., Li, J., Li, F., Meng, Q., Li, J., \& Xu, X. (2016). Energy consumption model and energy efficiency of machine tools: A comprehensive literature review. Journal of Cleaner Production, 112(5), 3721-3734. 